\title{
PRODUCTIVITY IMPROVEMENT USING VALUE STREAM MAPPING ON SEAT ASSEMBLY LINE
}

\author{
Najuka Mhase ${ }^{1}$, Mohit Shandilya ${ }^{2}$, Binayak Nag ${ }^{3}$, Gajanan Gambhire ${ }^{4}$ \\ ${ }^{1,2,3}$ Student, Industrial and Production Engineering Department, Vishwakarama Institute of Technology Pune, \\ Maharashtra, India \\ ${ }^{4}$ Assistant Professor, Industrial and Production Engineering Department, Vishwakarama Institute of Technology \\ Pune, Maharashtra, India
}

\begin{abstract}
In this competitive world, manufacturing companies has to look at redefining and redesigning of their production systems to attack the competitiveness demanded by the markets. The purpose of the paper is to know how value stream mapping (VSM) is used as a tool in implementing lean, to make improvements in the possible areas and to make modification from the current state to future state which helps in reducing the waste, eliminate non value added activities and increase productivity. A paper is based on the work that was carried out in an auto ancillary MNC company located in Pune. The aim of lean manufacturing is to reduce non value added activity, time to delivery, produce the quality products with economical and efficient manner with response to customer demand. The organizations which are practicing lean manufacturing have quality \& cost advantages compared to the organizations that are still using traditional production approach. The VSM process is simple and straight forward to implement. It always starts at customer demand and works back through documenting all processes and collecting data which is required for manufacturing of a product. It shows the map "Value stream" containing all the data such as work in process, cycle time, lead time, number of equipment's, operators and information flows. In this particular case even though we find out that the process can meet the existing demand but a slight increase in it would lead to occurrences of bottlenecks and thereby will be a hindrance to the entire production process. Thus productivity is enhanced by knowing the bottlenecks and by eliminating them.
\end{abstract}

Keywords: Value stream mapping, Lean manufacturing, Productivity Improvement $* * *$

\section{INTRODUCTION}

The case study deals with the productivity improvement using VSM on the seat assembly line. It is a lean venture towards perfection and an attempt to identify non-value adding activities thereby enhancing the productivity. With manufacturing becoming a more and more competitive market, companies globally strive to increase their efficiency. Increasing labor costs in many industrialized countries, as well as reducing and controlling operating costs, are just a few reasons companies choose to move or outsource their operations. Typically a majority of companies outsource to countries where wages are low and production costs are lower. To reduce cost and remain competitive with manufacturers abroad, companies use a variety of different methods. (Shook, 1999; R M Belokar, 2012)

\subsection{Car Assembly Terminology}

Seat assembly includes several operations that are carried out for different rows namely row 1 , row 2 , row 3. Row 1 and Row 2 have Left-hand side and Right hand side seats each. The third row is often referred as the "jump seat ". Each row has its own assembly line and a specified set of operations is carried out on these lines. Seat assembly is a Just in Time process in the company. The company follows the JIT principle and the demand by the customer is on daily basis. Daily demand for each row is different and this demand is communicated to the purchase planning and control department. Hence the inventory is managed using
Just in Time methodology.In the assembly line for W201, the three lines for each row are divided into the specific operations. The work to be done will be easily communicated to the worker since the set of the same car is manufactured as instructed by the customer online. Our variant is the SUV car seats and they involve the Left hand and Right hand side ( $\mathrm{LH}$ and $\mathrm{RH}$ ) in first and second row. The third row is the jump seat. From cushion loading to the final inspection, all the operations are carried out on the line till the unloading and dispatch of the sets assembled in that particular shift. (Automotive, 2009)

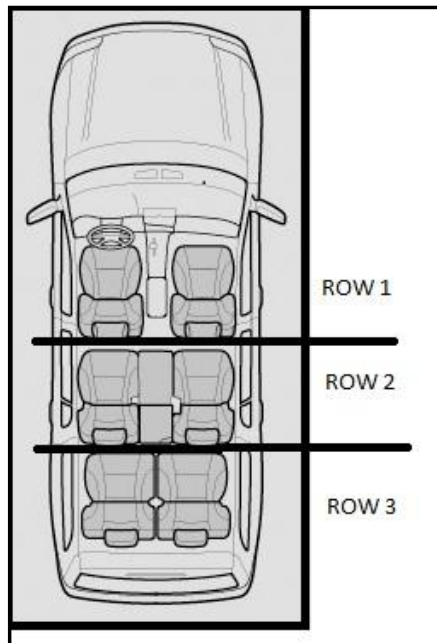

Fig.1. Car assembly terminology 


\subsection{Stations and Operations}

Each line is meant for each row and there are specific sets of operations that are carried out on the lines. They are discussed below row wise-

1) Cushion assembly-This activity is divided into the subassemblies that involve felt tape pasting, Machine assembly table assembly, inline connector mounting bracket with pop up rivets, assembly of lower bracket, rear cover bracket assembly etc.

2) Marriage assembly-This includes the fitment and mounting brackets, harness bush, felt tape pasting etc.

3) Riser assembly- It is the assembly of riser with frame.

4) Inner recliner covers assembly-Fitment of inner recliner of both sides.

5) Riser bolting-This includes the bolting operation on the riser of the seat

6) Seat belt buckles assembly

7) Plastic part assembly-Part 1 and Part 2

8) Final inspection

9) Online rework

\section{LITERATURE REVIEW}

1. Identify the product and product family..

2. Draw a current state value stream map, that will depict the exact flow of the processes along with the details of the processes.

3. Analyse the current state and cite for bottleneck.

4. Plot the future state map.

5. Implement the work

Above 5 steps shows the VSM methodology in precise which is duly implemented as seen in the case study. (Rajendra Kumar Gupta, 2014)

\subsection{Product Family and Flow Analysis}

The first step, identifying the product, consists of choosing which specific product the VSM will focus on. After the product used has been chosen, an initial VSM of the current process is created. Following the completion of the current map, the team evaluates the process and the steps involved. All this information is then compiled on a map and analysis is performed. On a typical VSM every step of the process is included. For each step, parameters could include cycle time, this product family is chosen to draw the VSM because it is the new line in the plant shifted from the another plant and needs to be observed and then remove the bottleneck from the given line. (Automotive, 2009)

After observing the assembly line we considered the product family as "FRAMES" that is the products or raw materials that are involved in the process flow. Here we analyze the operations that are being carried out and then identify the number of raw materials or the inventory that is needed for the activity on the particular station. Each row has its unique set of operations and hence unique set of raw material. The inventory is for one day. To observe the flow is the first step towards the value stream mapping and hence the flow from the inventory to the dispatch is observed along with the other details such as the cycle time and the changeover time and also the inventory at each station. It is thus evident that we must follow the flow process and then map the current state of our project for the specified value stream. This in the following topics we are discussing the entire flow and its analysis meant to map the current state of our VSM.

All the processes are monitored row wise on different days and then the cycle time for each is being calculated accordingly. Also the material requirement is calculated on each station having lead time one day.

\section{DATA COLLECTION}

Below is the series of operations carried out on the row 1,2.3 assembly line. Cycle time for each one was calculated by manual observation of each process and taking the average for the collected data. Now it can be easily observed that Total available time $=8$ hours shift - planned loss $=28800-3600=25200 \mathrm{sec}$.

Customer demand for row $1=160 /$ shift

All the data was collected to map the current stage of the VSM was mapped using the data. The data for row 1 and row 2 is attached in the annexure below.

\section{ANALYSIS OF THE CURRENT STATE MAP}

For the initial efforts in creating connected Value Stream continuous improvements by rapid action implementations are required rather than long term project planning and evaluating the process. The aim should be to improve respective employee's workstation with complete involvement right form operator to manager. The actions were focused on layout changing for assembly and raw materials.

The problem or bottleneck is classified according to the rows in the following discussions-

ROW 1- The takt time table shows that the bottleneck is not observed when the demand is 320 seats for this assembly line. The takt time here is 78.75 seconds. The operation or the process which is close to the takt time is the "seat belt buckle assembly" having cycle time of 74 seconds. However if the demand increases the takt time is certainly going to decrease and then this particular process or operation is likely to be the bottleneck of the entire assembly.

Let us consider the case if the demand is let's assume 360 seats, then the takt time will be 70 seconds and thus there seems a bottleneck in the process. Now the process needs the due monitoring and observation so that the non value added activities are removed from it.

Hence we focus on studying the process in detail and reduce the waste related to motion and over processing. Method study should be done for the same so that cycle time should be reduced.

ROW 2- The demand for the row 2 is 160 because it is the jump seat which comprises of one unit in each car set. Now 
the takt time for this row is 158 seconds and hence from the takt time table for row 2 assemblies and current state map it is evident that the bottleneck occurs at two operations namely-

1) Cushion complete assembly - Here the takt time is 158 seconds and the cycle time is 165 seconds. After observing the processes we can come to the conclusion that one of the causes here is excess material handling because the distance from the store rack to the assembly line is more than 10 meter which adds to the non value added time or Motion related waste in DOWNTIME. Also one fork lift and one fork lift operator is allocated to this task. Hence this adds up to the waste. Cushion assembly is the main bottleneck that is occurring in the line. Also this has to be tackled by reducing the inventory need by dividing the operations into twostations and having a cellular unit for each one so that the processes can be carried out within the takt time calculated.

2) Marriage Assembly- This operation has the cycle time of 165 seconds which is obviously less than the calculated takt time. In this operation the main waste is related to the inventory. Marriage assembly components are manufactured in one unit of the company from where they are procured and assembled on the line. Now the procured components fell short and cannot meet the demand. Also marriage assembly is the complicated task and needs skilled level worker for the same.
Also the scanning is to be done for the processes and it involves around 5 seconds for each scanning. Scanning of the barcode is their system of poka yoke.

ROW 3- From the current state it is clear that there is no bottleneck that can be seen in the processes of this assembly line. However if the demand increases and doubles itself in the due course of time, the takt time is halved and hence a bottleneck can be observed in the processes like those of Cushion assembly $\mathrm{LH}$ and $\mathrm{RH}$ and also in the trim cover assembly. However in the present scenario there is no bottleneck that is observed.

Thus this is the primary analysis that is done by mere observation and monitoring. Now detailed study is involved to verify the root cause of the problem and thus implement the kaizen. This is the step required for the future state of the VSM. NVA's are mainly created due to lack of material handlers, non standardized work, improper layout and equipment functionality, inappropriate line balancing, material shortage. To reduce these standard practices should be followed by operators with insurance that all the processes in the plant have the necessary material, qualified equipment and safety. Also getting one station offline and poka yoke would help to minimize these wastes which become our task in the further processes in stage 3 . Following are the graphs of the respective rows

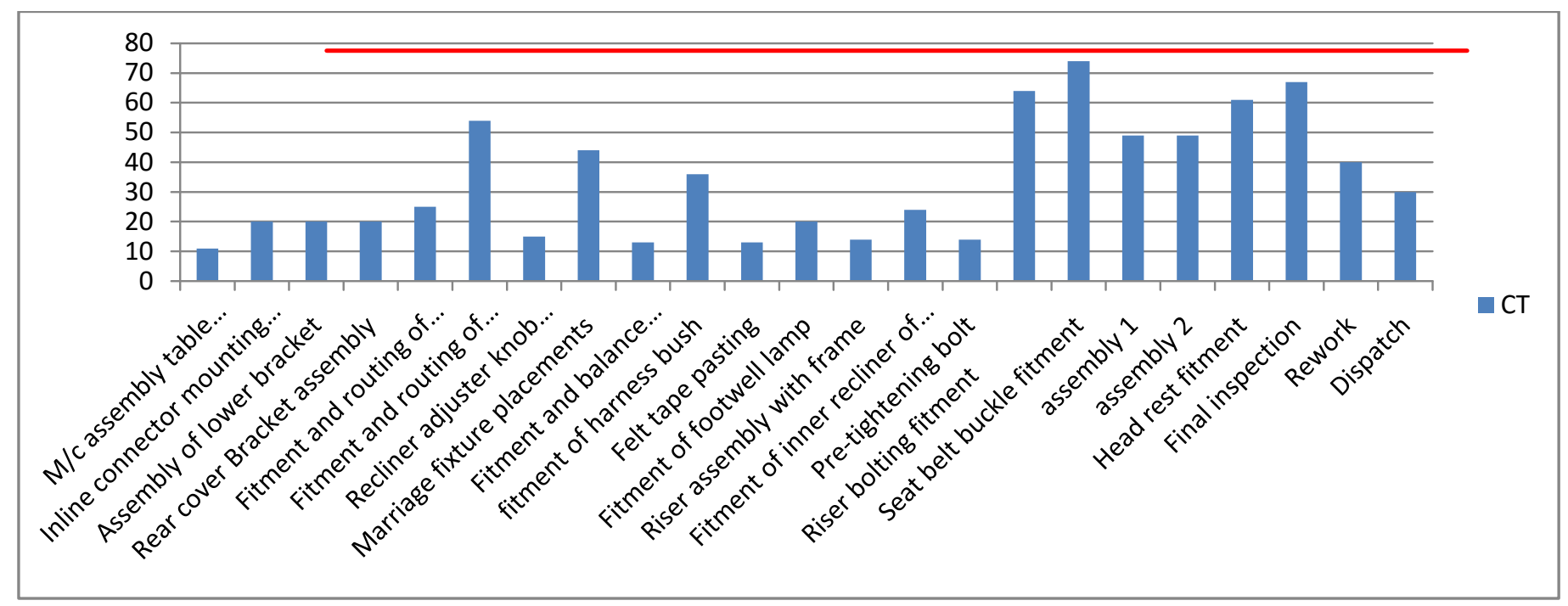

Chart 1. Graph of cycle time vs takt time calculations of Row 1

Above graph shows that there is the difference that can be seen between the Takt time and the cycle time but however for the first operations that is cushion assembly, it can be observed that the cycle time is more than the calculated takt time. Hence the bottleneck can be easily observed. The above table shows the series of operations carried out on the row 1 assembly line. Cycle time for each one was calculated by manual observation of each process and taking the average for the collected data. Now it can be easily observed that -

Total available time $=8$ hours shift - planned loss $=28800-3600=25200 \mathrm{sec}$.

Customer demand for row $1=160 /$ shift
One can observe it easily that even though the takt time that we have calculated is more than the cycle time but this is with respect to the current demand. However if the demand increases by a slight amount then there are chances that few of the operations in the assembly stations will become the bottlenecks and also it will be very difficult to carry out the daily production needs. Hence it should be noted that even calculating the takt time demand fluctuation should be considered and this will surely help to forecast the future state of our value stream. A value added activity becomes a non value added activity when demand fluctuates. we always need to consider this in mind and then analyze the current as well as future state of the VSM. 


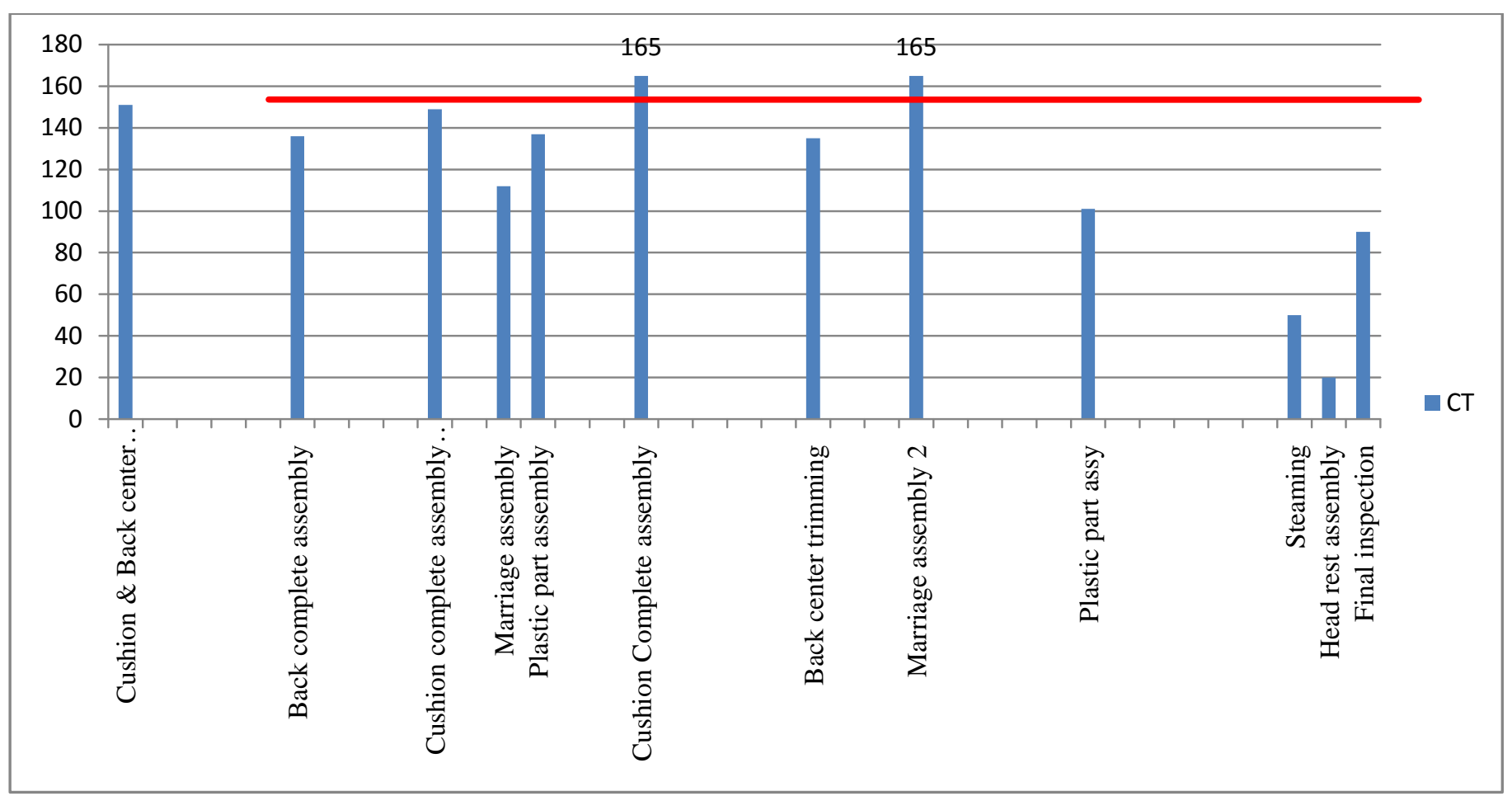

Chart 2. Graph of cycle time vs takt time of Row 2

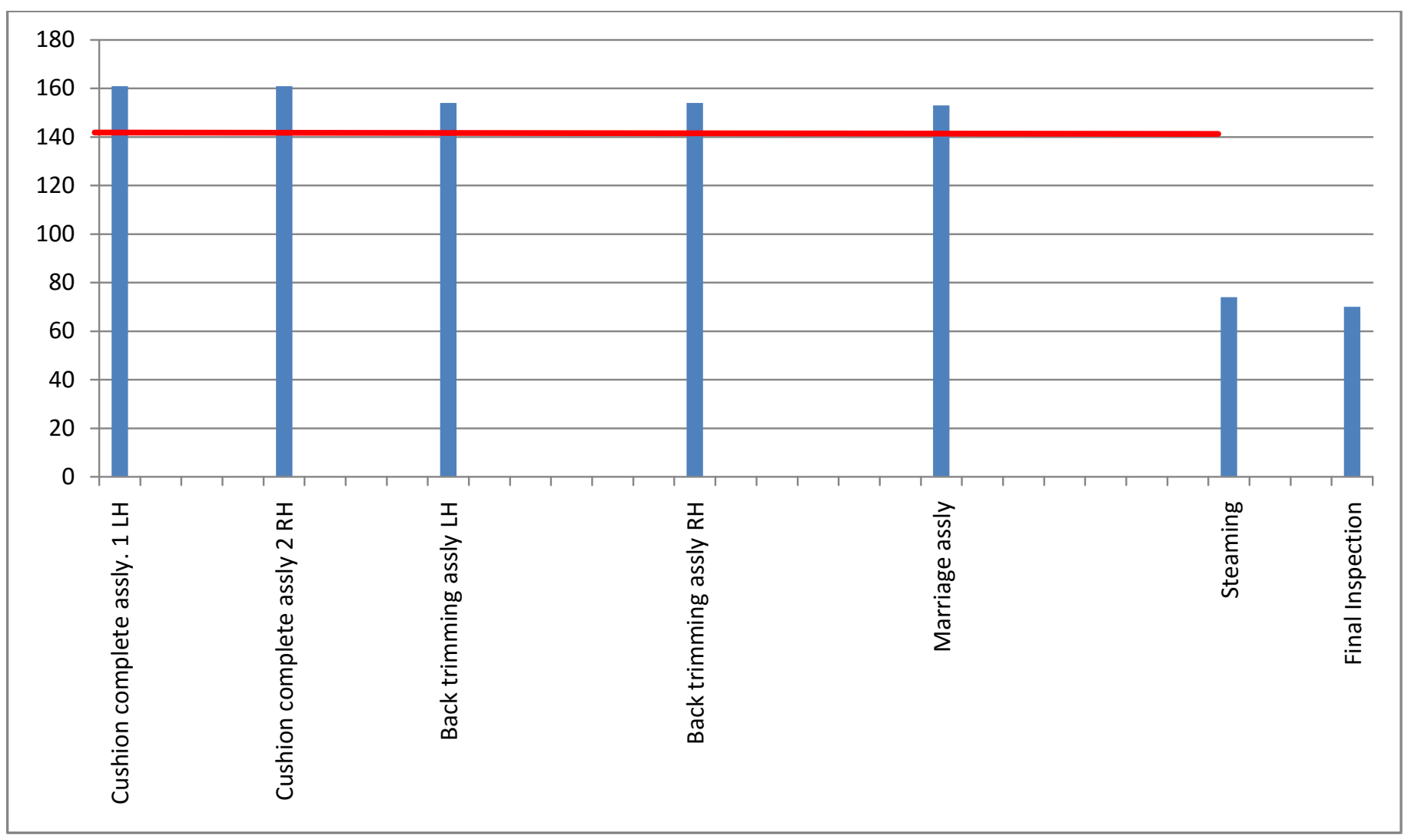

Chart 3. Graph of cycle time and takt time of Row 3 
Table 1. Table of Cycle time of the respective stations of the Row2 assembly line

\begin{tabular}{|c|c|c|c|c|c|}
\hline Sr.no. & Station Details & Activity & $\mathrm{CT}$ & Total CT & Man \\
\hline \multirow{5}{*}{1} & \multirow{5}{*}{ Cushion \& Back center trimming } & Back centre trimming & 30.00 & \multirow{5}{*}{151.00} & \multirow{5}{*}{2} \\
\hline & & Cushion centre trimming & 50.00 & & \\
\hline & & Cushion assembly & 12.00 & & \\
\hline & & Seat belt buckle. & 4.00 & & \\
\hline & & Foam assembly & 55.00 & & \\
\hline \multirow{4}{*}{2} & \multirow{4}{*}{ Back complete assembly } & Bezzel cover assembly & 21.00 & \multirow{4}{*}{136.00} & \multirow{4}{*}{1} \\
\hline & & Arm rest fitment & 32.00 & & \\
\hline & & Grommet assembly & 28.00 & & \\
\hline & & Back complete assembly 1 & 55.00 & & \\
\hline \multirow{2}{*}{3} & \multirow{2}{*}{ Cushion complete assembly with riser } & Riser assembly & 49.92 & \multirow{2}{*}{149.00} & \multirow{2}{*}{2} \\
\hline & & Riser assembly with cushion & 100.00 & & \\
\hline 4 & Marriage assembly 1 & Marriage assembly & 112.00 & 112.00 & 1 \\
\hline \multirow{3}{*}{5} & \multirow{3}{*}{ Plastic part assembly } & Banana cover assembly & 32.00 & \multirow{3}{*}{137.00} & \multirow{3}{*}{1} \\
\hline & & Recliner cover assembly & 44.00 & & \\
\hline & & Hard board fitment. & 61.00 & & \\
\hline \multirow{5}{*}{6} & \multirow{5}{*}{ Cushion Complete assembly } & Cushion folding & 20.00 & \multirow{5}{*}{165.00} & \multirow{5}{*}{1} \\
\hline & & Cushion assembly & 50.00 & & \\
\hline & & Seat belt buckle bar & 20.00 & & \\
\hline & & Riser bar and cushion & 45.00 & & \\
\hline & & Cushion trimming & 35.00 & & \\
\hline \multirow{3}{*}{7} & \multirow{3}{*}{ Back center trimming } & Back trimming & 70.00 & \multirow{3}{*}{135.00} & \multirow{3}{*}{1} \\
\hline & & Back assembly & 32.00 & & \\
\hline & & Bezzel cover assembly & 23.00 & & \\
\hline \multirow{5}{*}{8} & \multirow{5}{*}{ Marriage assembly 2} & Grommet fitment & 18.00 & \multirow{5}{*}{165.00} & \\
\hline & & Marriage assembly & 80.00 & & \\
\hline & & Lock nut assy & 13.00 & & 1 \\
\hline & & Front nut assembly & 34.00 & & \\
\hline & & Rear bottom cover fitment & 20.00 & & \\
\hline & & OB banana cover fitment & 13.00 & & \\
\hline & & OB recliner fitment & 19.00 & & \\
\hline & & IB banana cover fitment & 18.00 & & \\
\hline 9 & Piastic part assy & IB recliner cover fitment & 25.00 & 101.00 & 1 \\
\hline & & Pull cover fitment & 14.00 & & \\
\hline & & Side knob fitment & 12.00 & & \\
\hline 10 & Steaming & Steaming & 50.00 & 50.00 & 1 \\
\hline 11 & Head rest assembly & Head rest Fitment & 20.00 & 20.00 & 1 \\
\hline 12 & Final inspection & Final inspection & 90.00 & 90.00 & 1 \\
\hline
\end{tabular}

This is the data collection of the row 2 operation series collected in the tabular form. In the similar manner the data for row 1 and row 3 were collected so as to draw the current state of the value stream. It can be observed that stations have a series of operations and we have calculated the cycle time for each of these operations and a comparison can be made with the takt time in the value stream map in the current state. VSM is the pictorial representation of this data for the given assembly line that would just make the work tedious work of reading tables easy and get you the overall picture of the assembly line on a single page itself. 


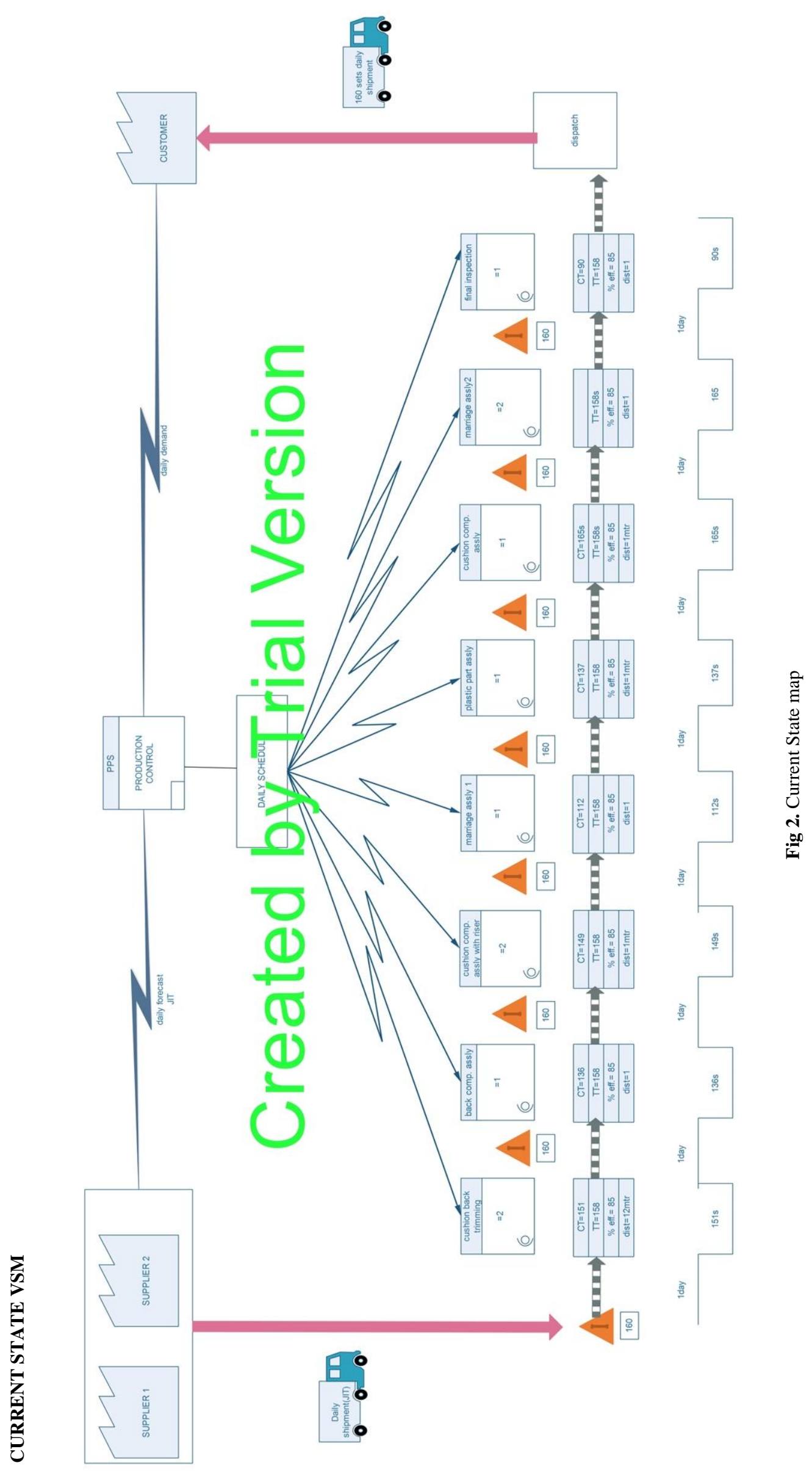




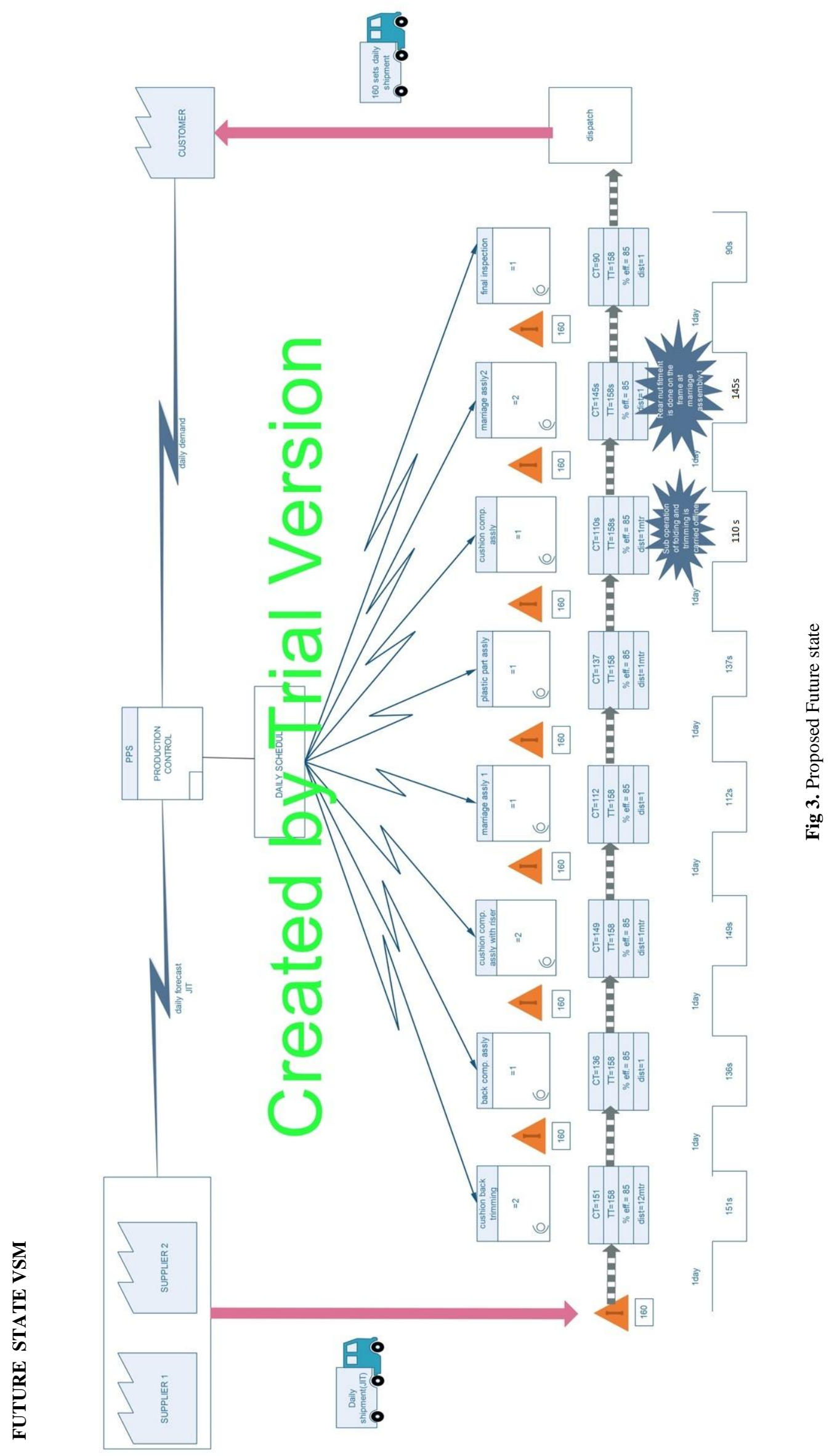




\section{FUTURE STATE}

Future state map of our process needs the keen monitoring and observation so that each and every bottleneck is studied and we can thus implement kaizen and reduce all the non value added activities. When the demand is more than the current demand which is 160 , let's say 180 takt time will be 70 for row 1 and 3 each and will be 140 for row 2 . The bottleneck operations in Row 2 are the cushion assembly and the marriage assembly 2. Now the Kaizen implementation will lead to the removal of these bottle necks. After the validation of the process it is clear that the cushion trimming and folding that comes under the cushion complete assembly will be moved to the cushion manufacturing centres itself. This reduces the cycle time of the station by $55 \mathrm{sec}$. and thus removes the bottleneck. Similarly the operation of Rear bottom cover fitment is shifted to the marriage assembly 1 which will help adjusting the cycle time of each process. Thus the two main bottlenecks are removed by shifting the position of the process and thus making that non value added activity into the value added activity.

\section{CONCLUSION}

Thus, it clearly indicates that the systematic application of value stream mapping process results in significant improvements in creating connected processes with continuous flow with reduction in non value added activities.

With mapping of the current state it can easily be seen that the VSM gives the clear identification of the problem and stage for improvement. Current state for the W201 line shows the bottleneck operations and hence we can take corrective or preventive action to remove the bottleneck.

The aim should be to improve respective employee's workstation with complete involvement right form operator to manager. The actions were focused on layout changing for assembly and raw materials. Hence we focus on studying the process in detail and reduce the waste related to motion and over processing. Method study should be done for the same so that cycle time should be reduced. Also the scanning is to be done for the processes and it involves around 5 seconds for each scanning. Scanning of the barcode is their system of poka yoke.

A successful lean implementation reduces the total lead time by incorporating lean improvements such as continuous flow, pull supermarkets, or FIFO lanes. As a result, each process produces only what customer's need, when they need it. Thus productivity is increased by $33 \%$ as thre cycle time is reduced.

\section{ACKNOWLEDGEMENT}

We are grateful to Prof. Gajanan Gambhire for his expert guidance and encouragement throughout the project from its start to end.

\section{REFERENCES}

[1]Automotive, L. (2009). A case Paper on VSM Halol Plant. Halol Lear Automotive Pvt. Ltd. , 200.

[2]Marcello Braglia, G. C. (2010). A NEW VALUE STREAM MAPPING APPROACH FOR COMPLEX PRODUCTION SYSTEMS . International Journal of Production Research, 45.

[3]R M Belokar, V. K. (2012). An application of Value stream mapping in Automotive Industry . IJITEEE , 6.

[4]Rajendra Kumar Gupta, D. M. (2014). Reduction of Wastage Using Value Stream Mapping: Case Study. IJRMET , 4.

[5]Rosario Domingo, R. A. (2007). Materials flow improvement in a lean assembly line: a case study . Assembly Automation , 7.

[6]Shook, M. R. (1999). Learning to see. Brooklyn, USA: Lean Enterprise Institue.

\section{BIOGRAPHIES}

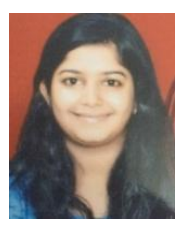

Najuka Mhase, B.Tech Industrial Engineering Student

Vishwakarma Institute of Technology

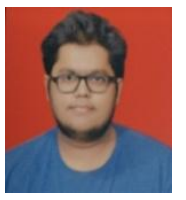

Mohit Shandilya, B.Tech Industrial Engineering Student

Vishwakarma Institute of Technology

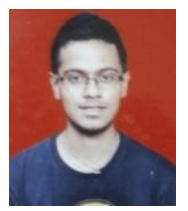

Binayak Nag, B.Tech Industrial Engineering Student

Vishwakarma Institute of Technology

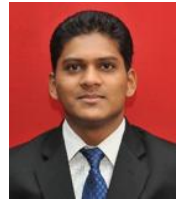

Prof. Gajanan Gambhire, Assistant Professor, Industrial and Production Engineering Department, Vishwakarama Institute of Technology 